\title{
Asi Havzasında Hidrometeorolojik Faktörler ve Akım Arasındaki İlişkinin Modellenmesi
}

\author{
Alişan NALCIOĞLU1 ${ }^{1}$, Mehmet ÜNSAL², Burcu ERCAN ${ }^{3}$, Ayşe Ece YAĞCI ${ }^{4}$ \\ 1,2,4Kahramanmaraş Sütçü İmam Üniversitesi, Mühendislik ve Mimarlık Fakültesi, İnşaat Mühendisliği Bölümü, Kahramanmaraş \\ ${ }^{3}$ Kilis 7 Aralık Üniversitesi, Mühendislik-Mimarlık Fakültesi, İnşaat Mühendisliği Bölümü, Kilis \\ ${ }^{1}$ https://orcid.org/0000-0001-7655-4307, ${ }^{2}$ https://orcid.org/0000-0001-5864-7040, ${ }^{3}$ https://orcid.org/0000-0002-3185-1831, \\ ${ }^{4} \mathrm{https}: / / o r c i d . o r g / 0000-0001-6973-9995$, \\ 凶: ayseeceyagci@ksu.edu.tr
}

\begin{abstract}
ÖZET
Dünya üzerinde birçok hava olayları, iklimsel değişiklikler ve su kullanımının planlanması hidrolojik döngüden etkilenirler. Su döngüsünün modellenmesi yağış değişkenliği ve taşkın için çok önemlidir. Bu çalışmada Asi Havzasına ait istasyonların 1962-2011 yılları arasındaki hidrometeorolojik parametreleri kullanılarak regresyon analizi yapılmıştır. Havzaya ait parametrelerin birbiriyle oluşturulan kombinasyonları ve akım ile ilişkileri DataFit programı aracılığı ile analiz edilmiştir. Analiz sonucunda en yüksek $\mathrm{R}^{2}$, OKH ve KOKH (hata oranları) değerleri incelendiğinde yağış-buharlaşmaakım modeli önerilmiştir. Ayrıca bu parametrelerin trend analizleri parametrik olmayan Mann Kendall Testi ile analiz edilmiştir. Asi Havzasını etkileyen 6 parametre için parametrelerin \%85 ve \%95 güven aralıklarındaki eğilimleri incelenmiştir.
\end{abstract}

\section{Modeling of Hydrometeorological Factors With Discharge in Asi Basin}

\section{Araştırma Makalesi}

$\begin{array}{ll}\text { Makale Tarihçesi } \\ \text { Geliş Tarihi } & : 24.09 .2019 \\ \text { Kabul Tarihi } & : 21.02 .2020\end{array}$

Anahtar Kelimeler

Datafit

Mann Kendall

Regresyon Analizi

\section{ABSTRACT}

Many weather events on the world, climatic changes and water use planning are affected by the hydrological cycle. The modeling of water cycle is very important for rainfall variability and flood. In this study, regression analysis was performed by using hydrometeorological parameters of Asi basin stations between 1962 and 2011. The relationship between the combinations of basin parameters with each other and relation with flood was analyzed by Datafit. As a result of the analysis, when the highest values of $\mathrm{R}^{2}$, MSE and RMSE (error rates) were examined, the rainfall - evapotranspiration - flow was determined to be the suggested model. In addition, trend analyses of these parameters were analyzed with the nonparametric Mann Kendall Test. The trends were examined in $85 \%$ and $95 \%$ confidence intervals for 6 parameters affecting the Asi Basin.

\section{Research Article}

$\begin{array}{ll}\text { Article History } & \\ \text { Received } & : 24.09 .2019 \\ \text { Accepted } & : 21.02 .2020\end{array}$

\section{Keywords}

Datafit

Mann Kendall

Regresyon Analysis

To Cite : Nalcıŏlu A, Ünsal M, Ercan B, Yağcı A. E 2020. Asi Havzasında Hidrometeorolojik Faktörler ve Akım Arasındaki İlişkinin Modellenmesi. KSÜ Tarım ve Doğa Derg 23 (6): 1510-1517. DOIः 10.18016/ksutarimdoga.vi.623770.

\section{GỉRİ̧̧}

İnsan yaşamının sürekliliği için su en temel kavramlardandır. İçilebilir su oranı tüm kaynakların $\% 1$ i kadardır. Su kaynağının sürekliliğinin sağlanmasında, planlanmasında ve işletilmesinde havza bazında çalışmak zorunludur (Göl, 2008).

Havza, bir akarsu tarafından parçalanan, etrafı dağ ve tepelerle çevrili olan, yüzeye geçen akımların bir yerde toplandığı ve aynı denize, ırmağa ve göle akan belirli bir arazi parçasıdır.

Ülkemiz su kaynaklarının planlanması açısından 26 adet havzaya ayrılmıştır. Su ile ilgili projelerin planlama, işletme ve bakım çalışmalarının en iyi şekilde yapılması için bu havzalarda hidrometeorolojik ölçüm ağı ve akım ölçümleri için çeşitli gözlem istasyonları kurulmuştur (Gencer ve ark., 2005).

Havzalarda nehrin akımını etkileyen birçok hidrometeorolojik parametre vardır. Yağış, Buharlaşma, Nem ve Rüzgar hızı bu parametrelerdendir. Havzada yağış ve akış sıkı bir ilişki içerisindedir. Yeraltı suları da havzada meydana gelen yağış ve akım ile ilişki içerisindedir. Havzalarda yağışın azalması feyezan akışlarını anında etkiler (Yurdakul, 1998). Buharlaşma havza yüzeyinde bulunan suyu sivi halden gaz hale gelmesidir. Buharlaşmanın ne derece olduğu havzada gerçekleşen ve gerçekleşecek olan akıma direkt olarak etkisi vardır. Buharlaşan su atmosfere döner ve tekrar yağış olarak havzaya ulaşır bu da havzadaki akımın direkt 
olarak etkilemektedir. Akış halinde bulunan nehir yatağında fazla sıcaklık etkisi altında buharlaşma ve bu buharlaşmanın devamında hidrometeorolojik denge gereği yoğunlaşması sonucu yağış olarak yeryüzüne düşer.

Asi Nehri Havzası son yıllarda hidrolojik karakteristik değişimlere sebep olmuştur. Bu değişimlerin sebebi havzadaki sanayi tesislerinin artmass, yapılan barajlar ve arazi kullanım çeşitliliğidir. Ayrıca bölgenin iklim özelliğinden kaynaklı bol yağış meydana gelmektedir. $\mathrm{Bu}$ durum bölgenin bozuk drenajı ve eğim düşüklüğünden dolayı taşkın tehlikesi oluşturur. Meydana gelen sel sularından oluşan taneli malzeme tarım alanlarında verimi azaltmıştır.

\begin{tabular}{lrrr}
$\mathrm{Bu}$ çalışmada & Asi Havzasını & etkileyen \\
hidrometeorolojik & \multicolumn{2}{c}{ parametrelerin } & çeşitli \\
kombinasyonlarla & havza üzerindeki & etkisi
\end{tabular} kombinasyonlarla havza üzerindeki etkisi
araştırılmıştır ve havzayı etkileyen hidrometeorolojik parametrelerin veri kombinasyonlarının Mann Kendall test yöntemi ile belirlenen güven aralıklarında eğilimleri kontrol edilmiştir.

\section{MATERYAL ve METOT}

\section{Regresyon Analizi}

İki veya daha çok değişken arasındaki ilişkiyi ölçmek için kullanılan regresyon analizi yöntemi mevcut değerlerle ileriye yönelik bilinmeyen verileri tahmin etmeye yardımcı olur. Regresyon analizleri değişken sayısına göre tekli ve çoklu regresyon olarak ikiye ayrılır. Tek değişkenli regresyon analizi ile bağımlı ve bağımsız değişkenler arasındaki doğrusal ilişkiyi temsil eden bir doğrunun denklemi formüle edilir. Çok değişkenli regresyon analizleri içinde bir adet bağımlı değişken ve birden fazla bağımsız değişkenin bulunduğu regresyon modelleri olarak tanımlanır.

$\mathrm{Bu}$ çalışmada, regresyon analizini, istatistiksel analizi ve grafik çizmeyi basitleştiren ve kullanımı kolay bir program olan Datafit kullanılmıştır. Regresyon modelleri, çözülürken belirtilen uygunluk kriterlerinin (Kalan Kareler Toplamı, Korelasyon Katsayısı, Düzeltilmiş Korelasyon Katsayısı veya Standart Hata) (datafit web sitesi) uygunluğuna göre otomatik olarak sıralanırlar. Birçok alt havza karakteristik özelliği (yağış, buharlaşma ve rüzgar) bağımsız değişkenler olarak analiz edilirken, yıllık akış miktarı çoklu regresyon denklemlerinde bağımlı değişkendir. Çoklu regresyon denklemlerinde bağıml değişkenin en iyi tahminini sağlayan bağımsız değişkenlerin kombinasyonunu belirlemeye yardımcı olmak için değişken seçim algoritması da gereklidir (Flynn, 2003).

\section{Model Doğrulaması İçin Seçilen Deneysel Çalışma}

Mann Kendall verilerin istatistiksel analizinde trendlerini tamamlamak için kullanılan parametrik olmayan bir test metotudur. Mann Kendall testinin çözümleme sırasında verilerin sabit bir dağılımla örtüşmesinin beklenmemesi yapılan çalışma için bir kolaylıktır. Testte parametrelere ait verilerde eksik veri olursa mevcut en küçük veri değeri ile eş tutulur ve çalışma kümesi içerisine dahil edilir (Gilbert, 1978). $\mathrm{Bu}$ test yönteminde parametrelere ait verilerin sıralamaları sayısal değer büyüklüklerinden daha önemlidir (Karabulut ve Cosun, 2009).

Mann Kendall testi kullanılan parametrelere ait verilerin trendlerini saptamak için istatistiksel anlamda artış veya azalış eğilimi olup olmadığını tespit etmek amacıyla kullanılmıştır (Büyükyıldız, 2004).

Non-parametrik bir test olan Mann Kendall testi Kendall's Tau olarak bilinen testin özel uygulamasıdır. Hidrometeorolojik zaman serilerinin trendlerinin belirlenmesinde yaygin olarak kullanılan bir metottur (Hirsch ve ark., 1982). Testte zamana göre sıralanmış $X_{1} X_{2} \quad \ldots . . X_{n}$ serileri $H_{0}$ hipotezine göre zamandan bağımsız ve lineer dağıtılmış rastgele değişkenlerdir. Alternatif $H_{1}$ hipotezine göre ise $k$ eşit değildir $j$ olmak üzere $k * j<n$ için seride $X_{k}$ ve $X_{j}$ değerlerinin dağılımı benzer değildir. $\mathrm{Bu}$ durum seride lineer bir durum olmadığını açıklar. Mann kendall testinin istatisliği $S$ aşağıdaki ifade ile açıklanır. Bu varyans değerinin de eşitlik değeri de gösterilmiştir.

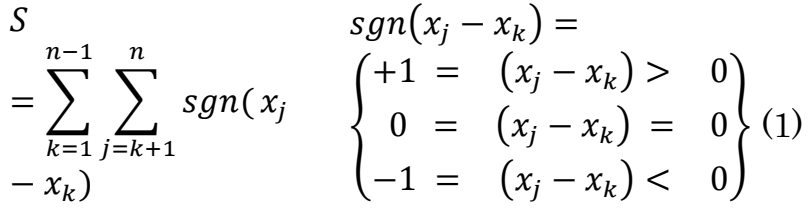

Asimptotik olarak normal bir dağglıma sahip ve ortalaması sıfır olan test istatisliği $S$ 'in varyansı

$\operatorname{Var}(s)=\frac{n *(n-1) *(2 n+5)}{18}(2)$ eşitliği ile hesaplanır.

Eğer zaman serisinde benzer değerler (bağ durumu) varsa varyans hesabi;

$\operatorname{Var}(s)=\frac{n *(n-1) *(2 n+5)-\sum t *(t-1) *(2 t+5)}{18}(3)$

şeklinde hesaplanır.

Süreklilik düzeltme birimi kullanılırsa $\mathrm{n}<10$ olmak üzere $S$ istatisliğinin teorik olasılık dağılımı için normal dağılım oldukça uygundur. Varyansı belirlenen Mann Kendall testinin önemli olup olmadığ standart normal değişken Z'nin aşağıdaki eşitlikle hesaplanıp kritik $\mathrm{z}$ değeriyle karşılaştırılmasıyla belirlenir.

Eğer seçilen $a$ önem seviyesinde $z<Z a^{2}$ ise $H_{0}$ hipotezi kabul edilir aksi halde reddedilir. Hesaplama $S$ değeri pozitif artan değeri negatif ise azalan bir trendin varlığ 1 söz konusudur. Bu metot eksik verilen varlığa müsaade ettiği ve verilerin belirli bir dağılıma uyma zorunluluğu olmadığı için kullanışlıdır (Yu ve ark., 1993). 


$$
Z=\left\{\begin{array}{ccc}
\frac{s-1}{\sqrt{\operatorname{Var}(s)}} & e \breve{\mathrm{g} e r} & s>0 \\
0 & e \breve{\mathrm{g} e r} & s=0 \\
\frac{s+1}{\sqrt{\operatorname{var}(s)}} & e \breve{\mathrm{g} e r} & s<0
\end{array}\right\}(4)
$$

Normal dağılıma sahip bir fonksiyonun olasılığ 0 ve standart sapma değeri de 1 alınarak denklem (5)'deki eşitlik kullanılarak anlamlılık derecesine göre değerlendirmeler yapılır.

$$
F(z)=\frac{1}{\sqrt{2 \pi}} e \frac{-z^{2}}{2}
$$

Yapılan çalışmada kullanılan parametreler için trend eğilimini belirlerken $\mathrm{z}$ ve $\mathrm{f}(\mathrm{z})$ değerlerini dikkate almaktayız. Burada $\mathrm{z}$ değeri negatif olursa ve $1.96<z<1.96$ şartı göz önünde bulundurulursa -1.96 dan küçük ise azalan bir eğilim göstermektedir. 1.96 dan büyük ise artan bir eğilim göstermektedir. Yine aynı $\mathrm{z}$ değeri eşitsizliğin içerisinde bir değere denk geliyor ise herhangi bir trend gözlenemez yorumunu yapmaktayız. Bu çalışmada giriş olarak kullanılan parametrelerden buharlaşma parametresinin $\mathrm{z}$ değeri -1.47221 olarak bulunmuştur. Bu parametre \%85 güven aralığı için azalan eğilim gösterirken $\% 95$ güven aralığında ise herhangi bir eğilim göstermemektedir.

\section{Asi Havzası}

Asi Nehri Havzası $24.660 \mathrm{~km}^{2}$ alan ile (\%69'u Suriye'de, \%23'ü Türkiye'de, \%8'i Lübnan'da) sınır oluşturan ve sınır aşan bir havza konumundadır. Asi nehrinin havzasinda son ylllarda sanayi tesislerinin artması, yapılan barajlar ve arazi kullanım çeşitliliği, hidrolojik karakteristik değişimlere sebep olmuştur. Ayrıca bölgenin iklim özelliğinden kaynaklı bol yağış meydana gelmektedir. Bu durum bölgenin bozuk drenajı ve eğim düşüklüğünden dolayı taşkın tehlikesi oluşturmaktadır. Meydana gelen sel sularından oluşan taneli malzeme tarım alanlarında verimi azaltmıştır.

Asi Havzasının yıllık yağış ortalaması 836.9 mm'dir. Havzanın yıllık sicaklık değeri $18.7{ }^{\circ} \mathrm{C}$ olarak ölçülmüştür. Havzanın ylllık buharlaşma değeri 1488.6 mm'dir. Havzanın su potansiyel değeri 2.23 milyar m³/yıl olarak belirtilmiştir (Avcı ve Yanık 1997).

\section{Data Fit}

Bu çalışmada kullanılan DataFit 7.1 programı çalışma yapılacak alana ait parametrelerin değerlerini uyumlu halde çalıştırmak üzere çeşitli modeller oluşturmaktadır. $\mathrm{Bu}$ modeller; grafikler ve denklemlerden oluşmaktadır. $\mathrm{Bu}$ grafik ve denklemlerden yola çıkarak yapılan tüm modellemeler arasinda en uyumlu model belirlenmek amaçlanmaktadır.

Programda çalışma yapılırken giriş verisi ve çıkış verisi olmak üzere iki ana veri girişi vardır. Çalışmada yapılan kombinasyonlar doğrultusunda giriş verileri birden fazla olabilmektedir.

Program girilen verileri baz alarak analiz yaparken Lineer analiz ve Nonlineer analiz yöntemlerini kullanır. Yapılacak olan analizlerde yine temelinde o analize ait denklemler vardır.

Lineer Denklem: Denklem terimleri 1. Dereceden veya sabit olan denklemlerdir. Bu denklemlere içerdikleri terim ve değişkenlerin düzlemde veya uzayda bir doğru ifade etmesinden dolayı doğrusal denklemde denilmektedir (Şekil 1.).

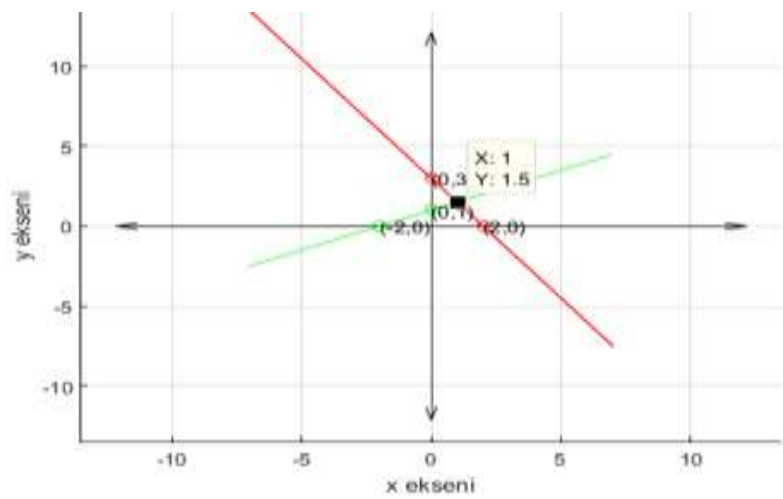

Şekil 1. Lineer Denklem Grafiği (Cömert 2020)

Figüre 1. Linear Equation Graph (Cömert 2020)

Nonlineer Denklem: İki veya daha yüksek dereceden polinomlar veya trigonometrik, logaritmik, üstel gibi lineer olmayan terimler içeren denklemlere non-lineer denklem denir (Şekil 2.).

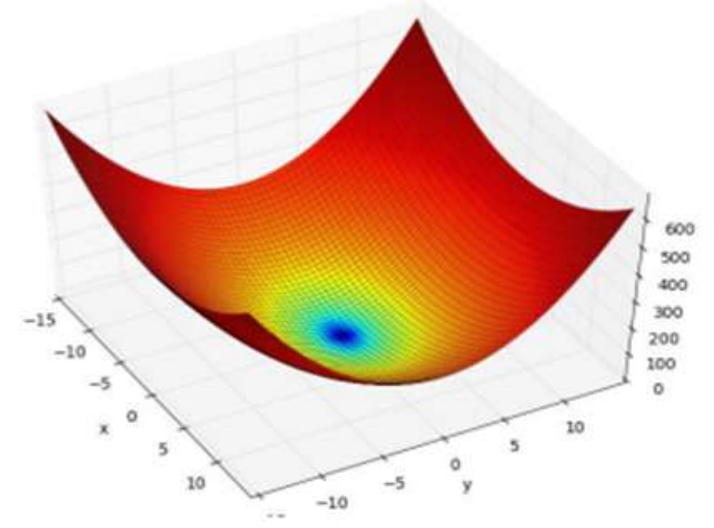

Şekil 2. Nonlineer Denklem Grafiği (URL 1) Figüre 2. Nonlinear Equation Graph (URL 1)

\section{BULGULAR ve TARTIŞMA}

Bu çalışmanın ilk bölümünde Asi Havzasını etkileyen hidrometeorolojik parametrelerin çeşitli kombinasyonlarla havza üzerindeki etkisi çalışılmıştır. Çalışmanın sonucunda elde edilen $\mathrm{R}^{2}$, OKH (Ortalama Karesel Hata) ve KOKH (Kök Ortalama Karesel Hata)değerleri karşılaştırılarak en uygun modelin hangi parametreler arasında olduğu 
belirlenmiştir. İkinci bölümünde ise Asi Havzasını etkileyen hidrometeorolojik parametrelerin veri kombinasyonlarının Mann Kendall test yöntemi ile belirlenen güven aralıklarında eğilimleri kontrol edilmiştir. Her iki bölümde çalışma yapılırken istasyon verileri kümülatif olarak alınmıştır.

\section{Regresyon Analizi}

Analiz parametrelerine ait değerler Asi Havzasinda bulunan istasyonlardan alınmış, çalışma yıl aralığı veri uygunluğu göz önüne alındığında 1962 - 2011 yılları arası olarak belirlenmiştir. Bu yıllar arasında bulunan verileri DataFit programina giriş yaparak parametrelerin arasındaki ilişki gözlemlenmiştir.

Çalışmada yağış, sıcaklık, nem, rüzgar ve buharlaşma gibi hidrometeorolojik veriler göz önüne alınmıştır. Bu parametrelerden yağış parametresi ilk baz alınan parametre olmuştur bunun nedeni ise yağışın akımı direkt olarak etkilemesidir.

$\mathrm{Bu}$ model çalışmasında çeşitli kombinasyonlar oluşturulmuşstur. Bu kombinasyonların akım değeri ile ilişkisi incelenmiştir. (Çizelge 1.)

DataFit 7.1 kullanılarak yapılan analiz çalışmasında hangi modelin diğerlerine göre daha uyumlu ve kullanılabilir olduğu modele ait $R^{2}$ veya grafiksel ifadelerden belirlenebilir. $\mathrm{Bu} \mathrm{R}^{2}$ değeri ve grafiksel ifadeler ise programın çözümlediği denklemlerden yola çıkarak belirlenir. Çalışmada yapılan 4 adet modele ait

Çizelge 2. Modellere ait denklemler

Table 2. Equations for models

\begin{tabular}{|c|c|c|}
\hline Model No & Denklem (Equation) & $\mathrm{R}^{2}$ \\
\hline Model - 1 & $A=a * Y^{10}+b * Y^{9}+c * Y^{8}+d * Y^{7}+e * Y^{6}+f * Y^{5}+g * Y^{4}+h * Y^{3}+i * Y^{2}+j * Y+\mathrm{k}$ & 0.9994 \\
\hline Model - 2 & $\begin{array}{c}A=a+b * \log (Y)+c * \log \left(Y^{2}\right)+d * \log \left(Y^{3}\right)+e * \log \left(Y^{4}\right)+ \\
f * \log \left(Y^{5}\right)+g * \log (N)+h * \log \left(N^{2}\right)+l * \log \left(N^{3}\right)+ \\
j * \log \left(N^{4}\right)+\mathrm{k} * \log \left(N^{5}\right)\end{array}$ & 0.9996 \\
\hline Model - 3 & $A=a+b / Y+c / Y^{2}+d / Y^{3}+e / Y^{4}+f / Y^{5}+g / B+h / B^{2}+i / B^{3}+j / B^{4}+k / B^{5}$ & 0.9996 \\
\hline Model - 4 & $\begin{array}{c}A=a+b / Y+c / Y^{2}+d / Y^{3}+e / Y^{4}+f / Y^{5}+g * \log (R)+h * \log \left(R^{2}\right)+l * \log \left(R^{3}\right)+j \\
* \log \left(R^{4}\right)+\mathrm{k} * \log \left(R^{5}\right)\end{array}$ & 0.9996 \\
\hline
\end{tabular}

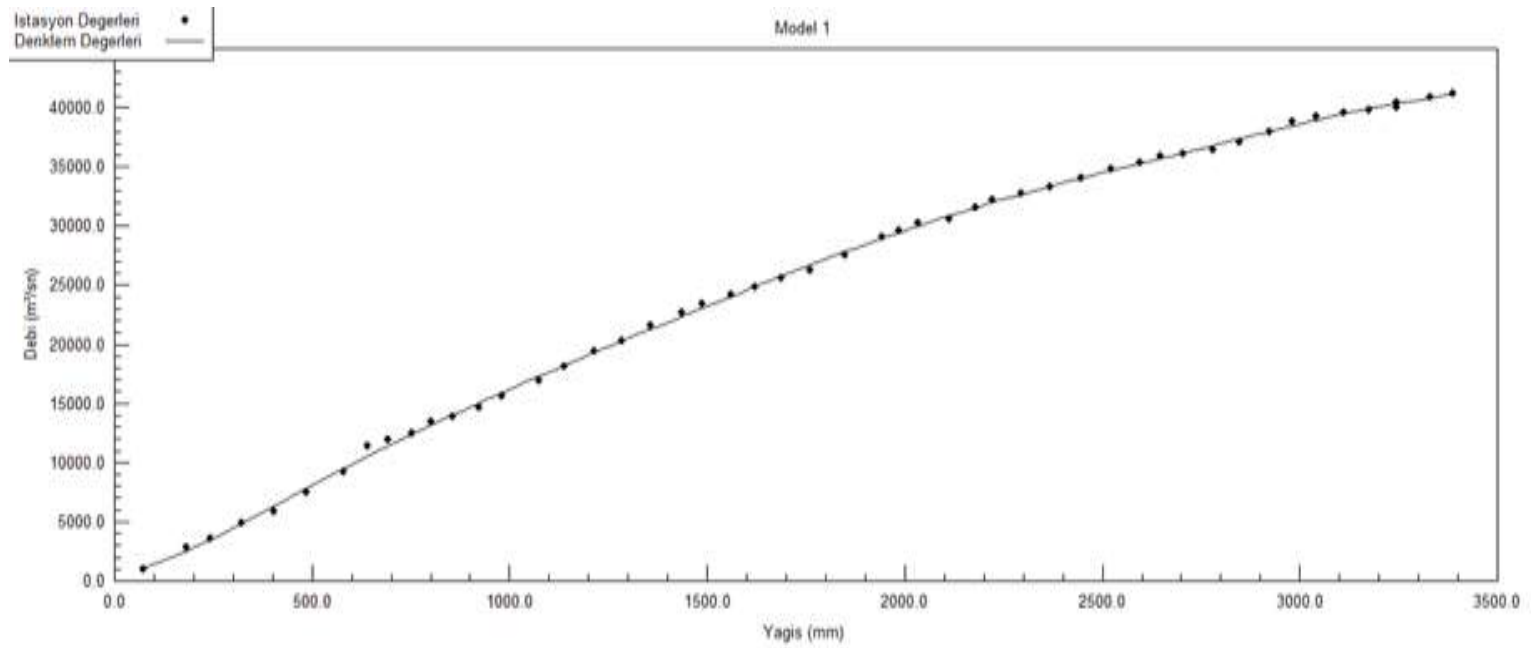

Şekil 3. Yağııs ve Akım İlişkisi (Model 1)

Figüre 3. Relationship between Rainfall and Flow (Model 1) en uygun denklemler aşağıda verilmiştir (Çizelge 2.). Bu çalışmada, $\mathrm{A}=\mathrm{Akım}, \mathrm{Y}=\mathrm{Yağ} 1$ ş, $\mathrm{N}=\mathrm{Nem}, \mathrm{B}=$ Buharlaşma ve $R=$ Rüzgar parametrelerini ifade etmektedir.

Çizelge 1. Programda kullanılan giriş ve çıkış parametreleri

Table 1. Input and output parameters used in program

\begin{tabular}{|c|c|c|}
\hline $\begin{array}{c}\text { Model No } \\
\text { (Model No) }\end{array}$ & $\begin{array}{c}\text { Giriş Verileri } \\
\text { (Input Data) }\end{array}$ & $\begin{array}{c}\text { Clkış Verileri } \\
\text { (Output Data) }\end{array}$ \\
\hline Model - 1 & Yağış & Akım \\
\hline Model -2 & Yağış, Nem & Akım \\
\hline Model - 3 & Yağış, Buharlaşma & Akım \\
\hline Model - 4 & Yağış, Rüzgar & Akım \\
\hline
\end{tabular}

Şekil $3^{6}$ de Model 1'e ait grafik verilmektedir. Grafikten görüleceği üzere yağış ile akım arasında çok yüksek bir uyum görülmektedir. Ayrıca $R^{2}=0.9994$ olarak elde edilmiştir. $\mathrm{Bu}$ modele ait $\mathrm{OKH}$ değeri 72034.95, KOKH değeri de 268.39 olarak bulunmuştur.

Şekil 4'de Model 2'ye ait grafik verilmektedir. Grafik incelendiğinde giriş verileri olan yağış - nem parametrelerinin çıkış verisi olan akım parametresi ile yüksek oranda uyum gösterdiği tespit edilmiştir. Bu parametreler sonucunda ortaya çıkan denkleme göre $R^{2}=0.9996$ olarak bulunmuş ve $O K H=48988.58$ iken $K O K H=221.33$ dir. 


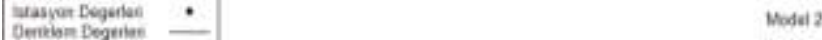

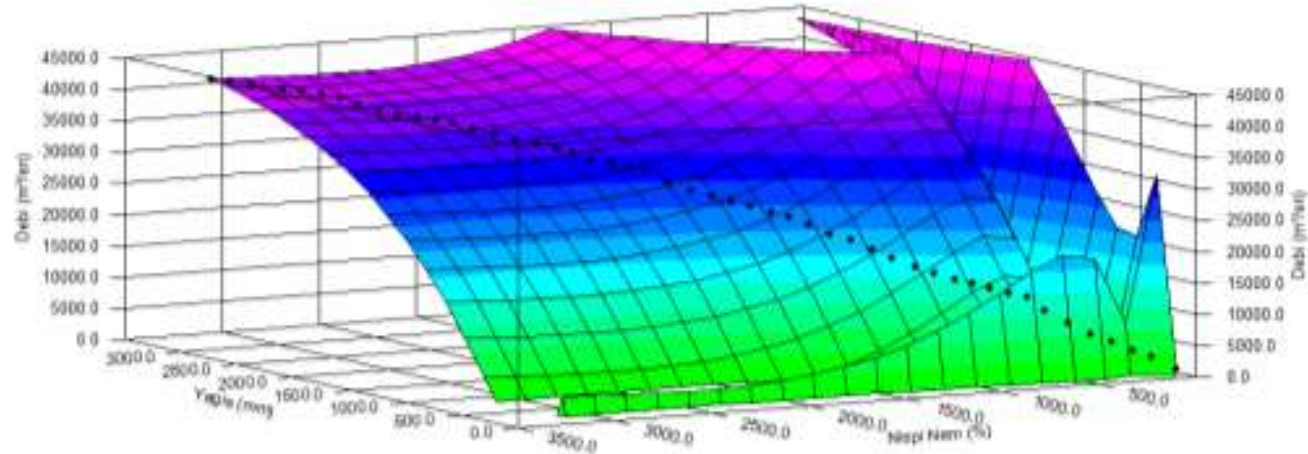

Şekil 4. Yağış, Nem ve Akım İlişkisi (Model 2)

Figure 4.. Relationship between Rainfall, Humidity and Flow (Model 2)

Şekil 5'te Model 3'ün uyumunu gösteren üç boyutlu grafik verilmiştir. Şekil 5'e bakıldığında giriş parametrelerinin oluşturduğu yüzeysel alan ile çıkış parametresi akımı simgeleyen noktasal veriler arası uyum gösterilmektedir. $\mathrm{Bu}$ kombinasyon çözümlendiğinde $R^{2}=0.9996$ olarak bulunmuştur. Yine kombinasyondan elde edilen diğer değerler $O K H=$ 44386.76 ve $K O K H=210.68$ dir.
Model4'e ait parametreler arası uyumu gösteren grafik yukarıda Şekil 6'da gösterilmiştir. $\mathrm{Bu}$ grafik incelendiğinde giriş ve çıkış parametreleri arasında oluşan uyum $R^{2}=0.9996$ ile diğer tüm modeller içerisinde en yüksek değerdedir. Bu modellemenin hata oranları olan $O K H=43026.02$ ve $K O K H=207.42$ olarak bulunmuştur.

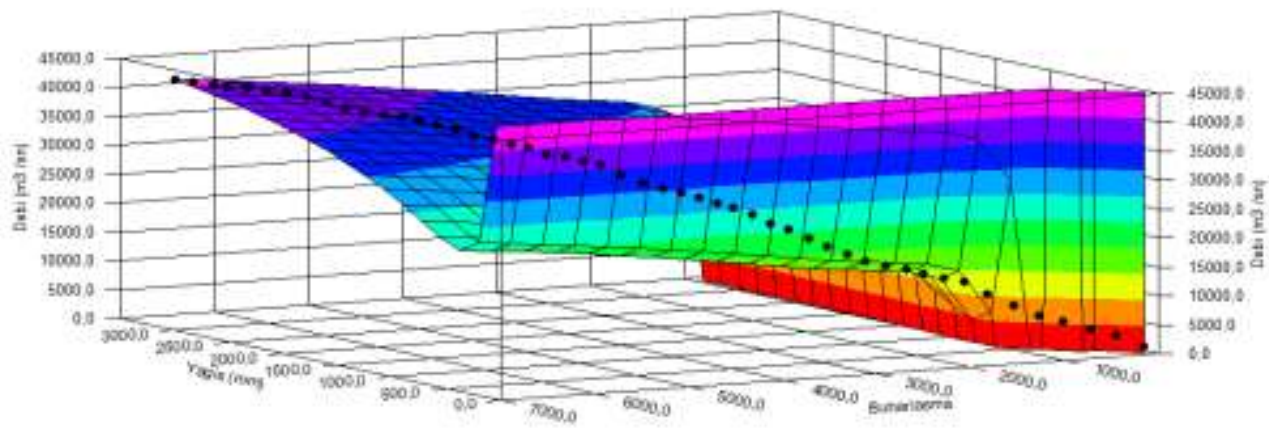

Şekil 5. Yağış, Buharlaşma ve Akım İlişkisi (Model 3)

Figure 5. Relationship between Rainfall, Evaporation and Flow (Model 3)

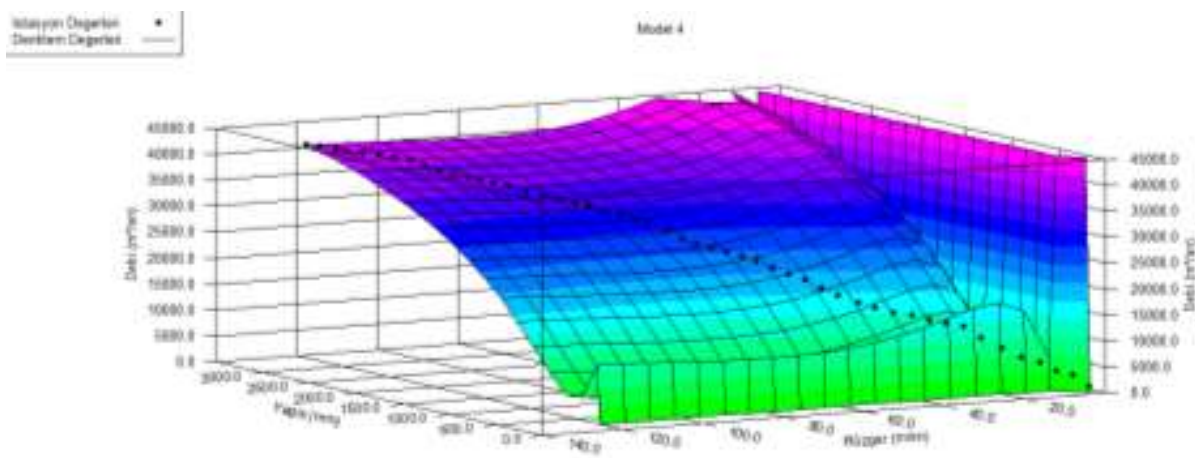

Şekil 6. Yağış, Rüzgar ve Akım İlişkisi (Model 4)

Figure 6. Relationship between Rainfall, Wind and Flow (Model 4) 
Çizelge 3. DATA FIT Programında Kullanılan Parametreler ve Sonuç Değerleri

Table 3. Parameters and Result Values Used in DATA FIT Program

\begin{tabular}{|c|c|c|c|c|c|c|}
\hline $\begin{array}{l}\text { Model No } \\
\text { Model No }\end{array}$ & $\begin{array}{l}\text { Giriş Verileri } \\
\text { Input Data }\end{array}$ & $\begin{array}{l}\text { Çıkış Verileri } \\
\text { Output Data }\end{array}$ & $\mathrm{R}^{2}$ & $\mathrm{Ra}^{2}$ & $\begin{array}{l}\text { OKH } \\
M S E\end{array}$ & $\begin{array}{l}\text { KOKH } \\
R M S E\end{array}$ \\
\hline Model - 1 & Yağış & Akım & 0.9994 & 0.9993 & $72.034,95$ & 268.39 \\
\hline Model - 2 & Yağış - Nem & Akım & 0.9996 & 0.9995 & $48.988,58$ & 221.33 \\
\hline Model -3 & Yağış - Buharlaşma & Akım & 0.9996 & 0.9996 & $44.386,76$ & 210.68 \\
\hline Model - 4 & Yağ1Ş - Rüzgar & Akım & 0.9996 & 0.9996 & $43.026,02$ & 207.42 \\
\hline
\end{tabular}

$R^{2}$ değeri regresyon analizinde yapılan kombinasyonları oluşturan parametrelerin nasıl bir uyum içerisinde çalışttğını gösterir.

Bu çalışmada kullandığımız veriler ve kombinasyonlar genel tabloda gösterilmiştir (Çizelge 3.). Ön çalışmada Havzaya ait istasyonların verileri kümülatif olarak programa giriş yapılmıştır. Regresyon analizinde kullandığımız DATA FIT programına giriş-çıkış verileri ve analiz sonucu ortaya çıkan regresyon katsayısı ve hata katsayıları gibi yorumlamaya yardımcı olacak verilere yer verilmiştir.

$R a^{2}$ değeri ise $R^{2}$ yi elde ettiğimiz formülde bulunan terimlere ait karmaşıklığı en aza indirmek için sonuca etki etmeyen modelleri formülden çıkartarak yeni ve daha uygun bir uyum değeridir.

OKH (Ortalama karasel hata) değeri ortalama karesel hata olarak adlandırılır. Regresyon eğrisinin noktasal

$$
\begin{aligned}
& R^{2}=1-\frac{\left(y_{i}-y_{i}^{n}\right)^{2}}{\left(y_{i}-y^{\prime}\right)^{2}} \\
& R a^{2}=1-\left(1-R^{2}\right) * \frac{n-1}{n-p-1} \\
& O K H=\frac{1}{n} * \sum_{j=1}^{n} e_{j}^{2} \\
& K O K H=\sqrt{\frac{\sum_{j=1}^{n} e_{j}^{2}}{n}} \\
& e_{j}{ }^{2}=\left(A_{j}-P_{j}\right)^{2}
\end{aligned}
$$

Burada $\left(y_{i}-y_{i}{ }^{n}\right)^{2}=$ atıkların kareler toplamı $(A K T)$, $\left(y_{i}-y^{\prime}\right)^{2}=$ her bir noktanın ortalamaya olan uzaklığ $\left(\right.$ OUKT),$A_{j}=$ gösterme biçimi, $P_{j}=$ gerçek değerlerin ortalaması, $n=$ hata değeridir. Çizelge 3. incelendiğinde $R^{2}$ değerleri tüm modeller için 0.9996 0.9938 arasındadır. Bu değerler tüm modeller için çok yüksek uyum olduğunu göstermektedir. Ancak $O K H$ ve $K O K H$ değerleri incelendiğinde modeller arası çok farklı değerler çıktığı görülmüştür. Çizelge 3 genel olarak değerlendirildiğinde $R^{2}=0.9996$ ve $O K H=$ 43.026,02, KOKH = 207.42 olan model -4 en iyi sonucu vermektedir. Analiz sonucu incelendiğinde en iyi sonucu model - 4 vermiş olsa da havzaya ait akım modellenmesinde model - 4'e en yakın ve akım parametresi üzerinde önemli etkisi bulunan buharlaşma parametresi ile oluşturulan Yağış, Buharlaşma yani Model - 3 ün tercih edilmesi verilere olan yakınlığını gösterir. $O K H$ hesap yapacak modelin tahmin performansı olup, her zaman pozitif değerdedir. $O K H$ değeri sıfıra ne kadar yakınsa tahmin performansı o kadar iyi olur.

KOKH ( Kök ortalama karesel hata) değeri kök ortalama karesel hata olarak adlandırılır. Hesap yapan modelin tahmin değeri ile gerçek değerin arasındaki uzaklığı belirlerken oluşan hata büyüklüğünü ölçen kuadratik bir metriktir. Burada oluşan hatalar regresyon hattının veri noktalarından ne kadar uzakta olduğunun ölçütü olup değeri sıfırdan sonsuza kadar gidebilen bir metriktir. KOKH değeri ne kadar negatif yönelimli olursa o kadar iyi bir tahmin performansı var demektir.

önerilmektedir.

$\mathrm{Bu}$ program kullanılarak, Kahramanmaraş Aksu Nehri'nin akım verileri modellenmiştir. Model sonucu akış tahmini için formülasyon üretilmiştir. $\mathrm{R}^{2}$ değeri 0.9878 elde edilmiştir. MSE 0.115752 , RMSE 0.340223 ve $A d j R^{2} 0.9874$ elde edilmiştir. Yapılan çalışmada, Datafit kullanılarak elde edilen model formülü ile Kahramanmaraş Aksu Nehri'nin yağışını tahmin etmek için uygulanabilir bir yaklaşım sunduğu ifade edilmiştir. (Ercan ve ark., 2019)

Literatürde yapılan çalışma ile mevcut çalışma benzerlik göstermekte ve desteklenmektedir. Ayrıca, Datafit yöntemi ile geliştirilen modellerin matematiksel formüllerinin elde edilebiliyor olması, yeni veriler eklenmesi durumunda akım tahmininde kolaylık sağlayacaktır. 


\section{Mann-Kendall Testi}

$\mathrm{Bu}$ çalışmada havzaya ait istasyon verileri tek bir veri olarak çalışılmış ve havzanın bütününü yansıtacak şekilde analiz edilmiştir. Asi Havzasını etkileyen parametrelerin $\% 85$ ve $\% 95$ güven aralıklarında eğilimleri incelendiğinde; \%85 güven aralığında yağ ${ }_{1 S ̧}$ parametresinde bir trend gözlemlenmemiştir. Bu iki parametre dışında diğer tüm parametrelerde azalan bir eğim mevcuttur. \%95 güven aralığ incelendiğinde akım, nem ve rüzgâr parametrelerinde azalan eğim gözlemlenmiştir. Buharlaşma ve yağış parametrelerinde bir trend gözlemlenmemiştir (Çizelge 4.).

Çizelge 4. Asi Havzası Hidrometeorolojik Parametrelerin Eğilim Analizleri Sonuçları

Table 4. Trend Analysis Results of Hydrometeorological Parameters in Asi Basin

\begin{tabular}{|c|c|c|c|}
\hline $\begin{array}{l}\text { Parametreler } \\
\text { Parameters }\end{array}$ & $\begin{array}{l}\mathrm{z} \text { değeri } \\
z \text { value }\end{array}$ & $\begin{array}{l}\text { Güven aralığı } \\
\text { Confidence Interval }\end{array}$ & $\begin{array}{l}\text { Eğilim } \\
\text { Trend }\end{array}$ \\
\hline \multirow{2}{*}{ Akım } & \multirow{2}{*}{-5.11929} & $\% 85$ & Azalan \\
\hline & & $\% 95$ & Azalan \\
\hline \multirow[b]{2}{*}{ Buharlaşma } & \multirow[b]{2}{*}{-1.47221} & $\% 85$ & Azalan \\
\hline & & $\% 95$ & $\begin{array}{l}\text { Trend } \\
\text { yok }\end{array}$ \\
\hline \multirow{2}{*}{ Nem } & \multirow{2}{*}{-2.05776} & $\% 85$ & Azalan \\
\hline & & $\% 95$ & Azalan \\
\hline \multirow{2}{*}{ Yağış } & \multirow{2}{*}{-1.07070} & $\% 85$ & $\begin{array}{l}\text { Trend } \\
\text { yok }\end{array}$ \\
\hline & & $\% 95$ & $\begin{array}{l}\text { Trend } \\
\text { yok }\end{array}$ \\
\hline \multirow{2}{*}{ Rüzgâr } & \multirow{2}{*}{-2.97789} & $\% 85$ & Azalan \\
\hline & & $\% 95$ & Azalan \\
\hline
\end{tabular}

\section{SONUÇLAR}

Bu çalışmanın ilk kısmında Asi Havzasını etkileyen hidrometeorolojik parametrelerden yağı,s, buharlaşma, rüzgâr, nem ve akımın birbirleriyle oluşturulmuş kombinasyonlarının uyumları incelenmiştir. Oluşturulan modellerde genel olarak $R^{2}$ değeri çok yüksek çıkmıştır. Bu modeller arasında Uyumluluk indeksi $R^{2}$ değeri ve hata oranını gösteren $O K H$ ve $K O K H$ değerleri göz önüne alındığında 4. Model olan Akım-Rüzgâr-Yağış modeli en yüksek uyum katsayısını ve en düşük hata değerini vermiştir. Analiz sonucu Model-4'e en yakın Model-3 gözlemlenmiştir. Model-3, akımın üzerinde önemli etkisi bulunan buharlaşma parametresini de içerisinde bulundurmaktadır. $\mathrm{Bu}$ sebeplerle havza akımı modellenirken Model-3'ün tercih edilmesi önerilmiştir.

Çalışmanın ikinci kısmında ise yine aynı parametrelerin trend analizleri yapılmış ve bu analizler yapılırken Mann-Kendall testi kullanılmıştır. Analizler $\% \quad 85$ ve $\% 95$ güven aralığında yapılmıştır.

Analiz sonuçlarına bakıldığında \% 85 güven aralığında akım, buharlaşma, nem ve rüzgar parametrelerinde azalan trend gözlemlenmiştir. Yağış parametresi için herhangi bir trend meydana gelmemiştir. \% 95 güven aralığına bakıldığında akım, nem ve rüzgar parametreleri için azalan bir trend meydana gelmiştir. Buharlaşma ve yağ ${ }_{\text {ş }}$ parametreleri için herhangi bir trend meydana gelmemiştir.

1962 - 2011 yılları arasındaki veriler dikkate alındığında \% 85 güven aralığında akım, buharlaşma, nem ve rüzgâr parametrelerinde, \% 95 güven aralığında akım, nem ve rüzgâr parametrelerinde düşüşler meydana gelmiştir.

\section{Çıkar Çatışması Beyanı}

Makale yazarları aralarında herhangi bir çıkar çatışması olmadığını beyan ederler.

\section{Araştırmacıların Katkı Oranı Beyan Özeti}

Yazarlar makaleye eşit oranda katkı sağlamış olduklarını beyan ederler.

\section{KAYNAKLAR}

Anonim 2010. Mak 210 Sayısal Analiz Bölüm 4- Lineer Olmayan Denklemlerin Çözümü. https://sayfam. btu. edu.tr/ upload/dosyalar/1427102727 bolum \%204-\%20lineer\%20olmayan\%20denklemlerın \%20 cozumu.pdf (Erişim Tarihi: 20.09.2019)

Avcı İ, Yanık B 1997. Sınırı Aşan ve Sınır Oluşturan $\mathrm{Su}$ Kaynaklarımız; Potansiyel Su Talepleri ve Sorunları. Makine Mühendisleri Odası ve 15 Diğer Meslek Odası İstanbul Şubeleri, Su Kongre ve Sergisi 97, İstanbul Sy: 7-15.

Büyükyıldız M 2004. Sakarya Havzası Yağışlarının Trend Analizi ve Stokastik Modellemesi. Selçuk Üniversitesi Fen Bilimleri Enstitüsü, İnșaat Mühendisliği Ana Bilim Dalı, Yüksek Lisans Tezi, $172 \mathrm{Sy}$.

Cömert Z, 2020. Lineer Denklem Sistemlerinin Analitik Çözümü. http://www.zafercomert.com/ IcerikDetay.aspx?zcms=106 (Erişim Tarihi: 20.09.2019)

Ercan B, Yağcı A E, Ünsal M 2019. Regresyon Analizi Yöntemi İle Kahramanmaraş Aksu Nehri'nin Akım Tahmini, International Symposium on Advanced Engineering Technologies İSADET, 2-4 May 2019, Kahramanmaras/Turkey.

Flynn R H 2003. Development of Regression Equations to Estimate Flow Durations and Low-FlowFrequency Statistics in New Hampshire Streams, Water-Resources Investigations Report 02-4298, Pembroke, New Hampshire.

Gencer M, Uğurlu A, Kacar M, Özcan H, Kesim A, Aydin B 2005. Hidrometeoroloji Ders Notu. https://www.mgm.gov.tr/FILES/genel/kitaplar/hidrometeoroloji.pdf

Gilbert R O 1978. Statistical Methods for Enviromental Pollution Monitoring, Van Nostrand, 


\section{New York}

Göl C 2008. Kentsel Su İhtiyacının Karşılanmasında Sürdürülebilir Havza Yönetimi, TMMOB 2. Su Politikası Kongresi, 20-22 Mart 2008. S.175.

Hirsch R M, Slack J R, Smith R A 1982. Technigues of Trend Analysis for Monthly Water Quality Data, Water Resources Research 18 (1) : $107-121$.

Karabulut M, Cosun F 2009. Kahramanmaraş İlinde
Yağışların Trend Analizi. Coğrafi Bilimler Dergisi CBD 7(1): $65-83$.

Yu Y. S, Zou S, Whittemore D 1993. Non-parametric Trend Analysis of Water Quality Data of Rivers in Kansas. Journal of Hydrology, 150 (1): 61-80.

Yurdakul M 1998. Bir Havzada Yağış, Akış ve Yeraltı Suyu Seviye Değişiminin İrdelenmesi. Jeoloji Mühendisliği Dergisi. 52: 50-56 